\title{
Surgical Repair of Inguinal Direct Hernia without Cremaster Resection
}

\author{
Reinaldo Silvestre* \\ Surgeon Professor, Santa Cruz del Norte, Cubat
}

Submission: March 16, 2017; Published: March 20, 2017

*Corresponding author: Reinaldo Silvestre, Surgeon Professor, Santa Cruz del Norte, Cuba, USA, Tel: 786-326-1002;

Email: doctorsilvestre@hotmail.com

\begin{abstract}
Preservation of the cremaster muscle during the surgical repair of the direct inguinal hernia.

keeping the funtion of the cremaster.

Cremaster muscle: The cremaster muscle is all around of the inguinal cord, the main funtion is elevation of the testis also is protecting the elements of the inguinal cord.

Concept: The direct inguinal hernia is locate at the triangule of Hesselbach of the inguinal region,this triangule components are the inguinal ligament of Poupart. The epigastric blood vessels pack close to the deep inguinal ring and the external border of the rectal muscle. That is the Hesselbach triangule and the main component of the wall in this triangule is the transversalis fascia. For that reason is the most weak point of the abdominal wall. History-Inguinal hernia repair has made enormous progress throughout the ages. Surgical techniques have rapidly evolved since Eduardo Bassini proposed his first procedure. When analyzing original articles since the sixteenth century, it becomes apparent that all surgical techniques for repair of the inguinal hernial orifice can be traced back to two simple repair principles. The first is reinforcement of the anterior wall of the inguinal canal and tightening of the external inguinal ring (Stromayr 1559, Purmann 1694, Czerny 1877) and the second is reinforcement of the posterior wall of the inguinal canal and the tightening of the internal inguinal ring, either externally (Lucas-Championnière 1881, Bassini 1889, Lotheissen 1898, McVay 1942, Shouldice 1945, Lichtenstein 1987, Stoppa 1989) or via an intraabdominal approach by laparotomy (Tait 1891) or laparoscopically (Ger 1990, Velez and Klein 1990). We have tried to provide a systematic order to the diverse procedures of surgery of inguinal hernias according to their repair principles. We also point out their historical development.
\end{abstract}

Indications: Any palpable mass,painful,that increase with any physical effort or Valsalva maniouver mean that the patient has an inguinal hernia,can be direct when is coming from the Hesselbach triangule or indirect whem arise into the inguinal canal,both need to have a surgical procedure to repair the defect.

Procedure: The most common procedures to repair the direct hernia are the Zimmerman and Mc Vay, but most of the surgeons actually prefer just to close the posterior wall (fascia transversalis) repairing the Hesselbach triangule.can be manually using non absorbible suture open surgery with a small incision or laparoscopic procedure, how the laparoscopic procedure dont perform disection of the cremaster muscle, we start to perform the open procedure the same way,and this approach was who show,that doing this kind of closing of the posterior wall we can preserve the funtion of the cremaster muscle. Ralph Ger described the first potential laparoscopic inguinal hernia repair in 1982. He describes a metallic clip applying device to close the hernia sac during laparotomy for other operations.

\section{Introduction}

He eventually describes one case of laparoscopic inguinal henria repair in a similar fashion with metallic lips only [1-5]. His approach was applicabe to hernia sacs with defects less than $1.25 \mathrm{~cm}$. He did not describe reconstructing the inguinal floor and his approach was not applicable for direct inguinal hernias. The first total extraperitoneal approach (TEP) to inguinal hernia repair was first described by McKernon and Laws in 1993. As with the transabdominal approach (TAPP), the principles touted by Rives and Stoppa for open preperitoneal repair of a large mesh providing coverage over all defects, distributing intraabdominal pressure over the large mesh area, and requiring minimal fixation, were primary principles of the laparoscopic approach to inguinal hernia repair. The indications for laparoscopic inguinal hernia repair, TAPP or TEP, are the same for open inguinal hernia repair. They may be ideal for bilateral inguinal hernias and recurrences from anterior approaches, but is also appropriate with unilateral primary hernias when the surgeon is comfortable with the technique. For young, active males with primary hernias, it may ofter decreased pain and 
an earlier return to activity. Prior lower abdominal surgery or pelvic radiation are strong relative contraindications, as these may make access to the preperitoneal space difficult.

\section{Conclusion}

We would like to mention that the open procedure with preservation of cremaster muscle had been the same results that the laparoscopic procedure, also in good hands is very fast procedure and less expensive ,because the surgeon dont need any special tools like the laparoscopic approach. The recovery time was the same,and the patient can go home the same day, also can be perform just with sedation and local anesthesic.

\section{References}

1. sages.org/wiki/laparoscopic-inguinal-hernia-repair.

2. Historical evolution of inguinal hernia repair. Department of General Surgery, University Hospital, Johann Wolfgang Goethe University, Theodor- Stern-Kai.

3. Silvestre Review of two hundred patient at National Hospital of La Habana,Cuba.

4. Eduardo Bassini-jurnaluldechirurgie.ro/jurnal/docs/jurnal311/ art\%2001_vol\%207_2011.

5. Original Articles-link.springer.com/article/10.1007/s002689900220.
Your next submission with Juniper Publishers will reach you the below assets

- Quality Editorial service

- Swift Peer Review

- Reprints availability

- E-prints Service

- Manuscript Podcast for convenient understanding

- Global attainment for your research

- Manuscript accessibility in different formats ( Pdf, E-pub, Full Text, Audio)

- Unceasing customer service

Track the below URL for one-step submission https://juniperpublishers.com/online-submission.php 